\title{
Feasibility Assessment of Low lodine Flow Rate Imaging in Abdominal Contrast-enhanced CT
}

\author{
Ye LI ${ }^{1}$, Hui-mao ZHANG ${ }^{2}$ and Hong-yan LI $^{\star}$ \\ ${ }^{1}$ Department of Radiology, First Hospital of JiLin University,China \\ ${ }^{2}$ Department of Radiology, First Hospital of JiLin University, China \\ *Department of Urology,China-Japan Union Hospital of JiLin University,China
}

Keywords: IFR, lopromide 370, Contrast-enhanced CT.

\begin{abstract}
To assess the feasibility of abdominal contrast-enhanced CT imaging using low iodine flow rate .40 consecutive patients referred for abdominal contrast-enhanced CT imaging of upper abdomen were enrolled in this study,and were randomized into 2 groups according to different injection protocols. 28 grams of iodine was injected at a flow rate of $1.4 \mathrm{~g} \mathrm{I} / \mathrm{s}$ in Group A(Iopromide $370 \mathrm{mg} \mathrm{I} / \mathrm{ml}, \mathrm{n}=20) ; 24$ grams of iodine was injected at a flow rate of $1.2 \mathrm{~g} \mathrm{I} / \mathrm{s}$ in Group B (Iopromide $370 \mathrm{mg} \mathrm{I} / \mathrm{ml}, \mathrm{n}=20$ ). Data analysis was performed in all 40 patients. There were no significant differences in five point scale for patients between 2 groups, with $\mathrm{p}$ value $>0.05$. There were no significant differences in CNR, SNR and CT attenuation for patients between 2 groups.Low IFR imaging is feasible in the abdominal CM-enhanced CT, without the sacrifice of the image quality.
\end{abstract}

\section{Introduction}

Since its advent, there have been continuing advances in computed tomographic (CT) technology that have provided us with ongoing opportunities to improve the image quality and our clinical practice. In particular, during the past decade, the dramatically improved spatial and temporal resolution achievable at multi-detector CT has allowed previously highly technically demanding clinical applications such as CT angiography and cardiac CT to be practiced routinely.Contrast material-enhanced computed tomography (CT) is the most commonly used imaging modality for the detection and characterization of liver mass[1,2].Many protocols have been described in the literature for performing dynamic contrast material-enhanced multi- detector row helical computed tomographic (CT) imaging of the adult abdomen. The simplest, easiest, and most widely prescribed technique uses a fixed contrast material dose and a fixed rate of contrast material administration[3,4].For example, one patient referred to a tri-phase computed tomographic examination of abdomen usually received contrast material in iodine flow rate $(1.4 \mathrm{~g} / \mathrm{s}$ ) for $20 \mathrm{sec}$, then we can get satisfied image quality. Factors that have an impact on CM enhancement include CM dose, injection rate, and cardiac output ${ }^{5}$.Another important parameter is the distribution volume of the $\mathrm{CM}$, i.e. the intra- and extravascular extracellular spaces, which are both related to body size[6].

The use of contrast material should be according to the rule of as low as reasonably achievable, we think it may mean lower contrast material dose. So the purpose of this study is to assess the feasibility of abdominal contrast-enhanced CT imaging using low iodine flow rate. 


\section{Materials and Methods}

\section{Patient}

40 consecutive patients referred clinically for upper abdominal tri-phase contrast-enhanced CT were enrolled in this study.

\section{Contrast Material Injection and CT Scan Protocols}

Body weight (BW) and body height were measured before the examination. Body mass index(BMI) were calculated as follows:

Men and Women: Weight (kg)/Height $(\mathrm{m})^{2}$.

All studies were acquired with a multidetector CT scanner(Discovery HD 750, Gemstone Spectral Imaging, GE Healthcare, Milwaukee, Wis),

By using a random-number table, patients were prospectively randomized into two protocol groups of 20 patients each:

Group A, in which patients received $1.4 \mathrm{~g} \mathrm{I} / \mathrm{s}$ ( Iopromide $370 \mathrm{mg} \mathrm{I} / \mathrm{ml}$ ) for 20s;

Group B, in which patients received $1.2 \mathrm{~g} \mathrm{I} / \mathrm{s}$ (Iopromide $370 \mathrm{mg} \mathrm{I} / \mathrm{ml}$ ) for 20s;

\section{Quantitative Analysis of the Images}

These measurements were obtained in one session by a radiologist manually placing a circular region of interest at each anatomic site mentioned below. The region of interest was $1.0 \mathrm{~cm} 2$ for abdominal aorta and latissimus dorsi muscle. Care was taken to avoid any partial volume effects and not to include any visible vessels and areas with inhomogeneous attenuation in the aorta.

Signal intensity and noise. - In all 40 subjects, we measured the signal intensity (mean CT number in Housefield units) and noise (standard deviation of the CT number in Houns field units) in abdominal aorta. In each patient, the mean signal intensity(SI), and noise were calculated by averaging the values of the three ROI of abdominal aorta. The signal-to-noise ratio (SNR) was calculated as follows:

$\mathrm{SNR}=$ mean $\mathrm{SI} /$ mean noise.

Contrast and noise. - For each image, the contrast measurement represents the difference between the mean signal intensity of abdominal aorta and the signal intensity of the latissimus dorsimuscle. The contrast-to-noise ratio (CNR) was calculated as follows:CNR $=$ (mean SI - SI of latissimus dorsi)/(mean noise).

\section{Statistical Analysis}

Analyses were performed by using statistical software (SPSS version 22; IBM SPSS, Armonk, New York, USA).

A statistically significant difference was defined at a $\mathrm{P}$ value less than .05 . Continuous variables were expressed as mean \pm standard deviation.

\section{Result}

There was no significant difference in sex composition, age, BW and BMI among the four groups (all $P>.05$ ) 
The Kolmogorov-Smirnov test confirmed a normal distribution $(p>0.10)$ for the following parameters in four groups:age, BW, BMI, CT attenuation, iodine content, SNR, CNR and noise.

Table 1 Patient cohort according to IFR and CM

\begin{tabular}{|r|c|c|c|r|c|}
\hline $\begin{array}{c}\text { Gr } \\
\text { oup }\end{array}$ & $\begin{array}{c}\text { Contrast } \\
\text { Material(C } \\
\mathrm{M})\end{array}$ & $\begin{array}{c}\text { Iodi } \\
\text { ne } \\
\text { flow } \\
\text { rate }\end{array}$ & $\begin{array}{c}\mathrm{CM} \\
\text { injection } \\
\text { rate }\end{array}$ & $\begin{array}{c}\mathrm{CM} \\
\text { volume }\end{array}$ & $\begin{array}{c}\text { Total } \\
\text { Iodine } \\
\text { grams }\end{array}$ \\
\hline A & $\begin{array}{c}\text { Iopromide } \\
370\end{array}$ & $\begin{array}{c}1.4 \mathrm{~g} / \\
\mathrm{sec}\end{array}$ & $4 \mathrm{ml} / \mathrm{sec}$ & $80 \mathrm{ml}$ & $28 \mathrm{~g}$ \\
\hline B & $\begin{array}{c}\text { Iopromide } \\
370\end{array}$ & $\begin{array}{c}1.2 \mathrm{~g} / \\
\mathrm{sec}\end{array}$ & $3.4 \mathrm{ml} / \mathrm{sec}$ & $68 \mathrm{ml}$ & $24 \mathrm{~g}$ \\
\hline
\end{tabular}

Table 2 patient data in two groups

\begin{tabular}{|l|c|c|c|}
\hline parameters & Group A & Group B & P value \\
\hline Age & $51 \pm 12.5$ & $52 \pm 12.9$ & $\mathrm{p}=0.871$ \\
\hline Female:male & $7: 13$ & $8: 12$ & $\mathrm{p}=0.138$ \\
\hline Body weight(BW) & $65.5 \pm 9.0$ & $63 \pm 10.9$ & $\mathrm{p}=0.709$ \\
\hline Body mass index(BMI) & $23.1 \pm 2.3$ & $24.1 \pm 3.5$ & $\mathrm{p}=0.659$ \\
\hline
\end{tabular}

No significant differences were found between the two groups in terms of age, gender, BW and BMI (all P > 0.05)

Table 3 Quantitative Image Analys is of four Protocols

\begin{tabular}{|c|c|c|c|}
\hline parameters & Group A & Group B & P value \\
\hline SNR & $17.3 \pm 4.2$ & $20.0 \pm 6.0$ & $\mathrm{p}=0.055$ \\
\hline CNR & $14.1 \pm 4.0$ & $16.3 \pm 5.6$ & $\mathrm{p}=0.115$ \\
\hline CT attenuation & $382.9 \pm 68.4$ & $382.2 \pm 76.7$ & $\mathrm{p}=0.08$ \\
\hline
\end{tabular}

No significant differences were found between the two groups.

\section{Discussion}

Iodine flow rate means iodine content which is injected into the human body per second. $1.4 \mathrm{~g}$ / 1 iodine flow rate is carried out on the abdomen enhanced CT the most common clinical parameters on us, but that does not mean that is the most appropriate. Through this study can be found in low-iodine flow rate imaging, radiology doctors subjective ratings, objective evaluation (cnr, snr, ct value, etc.) no differences between each other, indicating that when 
iodine flow rate decreases, the picture still meet clinical needs. This study demonstrated that reducing the flow rate of the image of iodine still meet the clinical demand, so in clinical work, we want to lower iodine flow rate imaging.

\section{Conclusions}

No significant differences in SNR, CNR, CT attenuation were objected. There were no significant differences in subjective image quality scale, and it demonstrated that contrast-enhanced CT imaging in abdomen with low IFR is feasible.

\section{Acknowledgement}

This research was financially supported by the First Hospital of JiLin University.

\section{References}

[1] Haider MA , Amitai MM , Rappaport DC ,et al . Multi-detector row helical CT in preoperative assessment of small $(\leq 1.5 \mathrm{~cm})$ liver metastases: is thinner collimation better? Radiology $2002 ; 225: 137-142$.

[2] Kormano M, Partanen K, Soimakallio S ,Kivimaki T . Dynamic contrast enhancement of the upper abdomen: effect of contrast medium and body weight . Invest Radiol 1983; $18: 364$ -367 .

[3] Saini S. Multi-detector row CT: principles and practice for abdominal applications. Radiology 2004;233:323-327.

[4] Hallynck TH, Soep HH, Thomis JA, Boelaert J, Daneels R, Dettli L. Should clearance be normalised to body surface or to lean body mass? Br J Clin Pharmacol 1981;11:523-526.

[5] Kim T, Murakami T, Takahashi S, et al. Effects of injection rates of contrast material on arterial phase hepatic CT. Am J Roentgenol1998;171:429-32.

[6] Kormano M, Partanen K, Soimakallio S, et al. Dynamic contrast enhancement of upper abdomen: Effect of contrast medium and body weight. Invest Radiol 1983;18:364-7. 